\title{
Organizational and technological reliability of the cluster formation of urban residential development
}

\author{
Mikhail Semenenko ${ }^{1, *}$ and Aida Mirzakhanova ${ }^{1}$ \\ ${ }^{1}$ Moscow State University of Civil Engineering, 26, Yaroslavskoye Shosse, 129337, Moscow, Russia
}

\begin{abstract}
The purpose of this study is to determine the deterministic meaning of the term "Cluster of urban residential development" used in organizing the re-profiling of urban areas taking into account the organizational and technological model of production reliability. When implementing such projects, a set complex of combined tasks of an organizational and technological profile is solved and a number of parameters are taken into account (comfortable living, with rationally used free space; a combination of residential buildings with social, educational, cultural, everyday and entertainment facilities, etc.), as well - the basic principles of the formation of the reliability of the organizational and technological model of a cluster of urban residential development. The fundamental scientific hypothesis is that using the methods of organizational, technological, as well as numerical modelling and system engineering, the indicators of the integral reliability of construction manufacturing can be increased. As a result of the study, the cluster parameters of the urban residential for use in the complex model are established.
\end{abstract}

\section{Introduction}

When designing high-class housing for a person, a number of requirements and factors that affect the quality of the living environment should be taken into account. One of the most important issues is the consideration of climatic conditions, social spheres of activity, construction, architectural and economic requirements.

Particularly serious today are issues of an economic nature. The solution to this issue refers to a careful attitude to depleted natural resources, account the prevailing winds, the characteristic terrain and waste management - all this must be taken into account when operating residential buildings.

Creating the most comfortable living conditions is the main goal for creating the structure of space organization. This is clearly expressed in the creation of "quiet circuits," where the forming figure is a closed perimeter of a group of structures, which in turn creates a yard territory protected from traffic flows and aimed at reducing urban noise and wind.

\footnotetext{
*Corresponding author: MikhailSemenenko@mail.ru
} 


\section{Materials and methods}

To achieve the effective implementation of the urban complex of the quarterly build-up, it is appropriate to use technical, material, intellectual and temporary resources and, in turn, reduces the risks during the realization of the quarterly type integrated urban build-up.

Ensuring reliability in the formation of cluster urban residential development and high social and economic efficiency in the implementation of the project is the main goal in developing the organizational and technological model. [6]

From all of the above, one can form the main goal - the achievement and balanced solution of many problems: economic, technical and technological, social, environmental. The solution to these issues will allow you to take control of the parameters and correct them at any stage of the project. The goals and objectives of several levels, determined by the nature of the enterprise activity in the project implementation, are means to achieve the main goal of the organizational and production model. Setting goals and objectives by priority will allow you to make adjustments to the implementation of the project and assess possible risks at any stage of the facility being built.

One of the main problems of recent years is the complexity and reliability of the implementation of cluster urban residential building-up [5]. This is associated with a large territory, multitasking and risks in the implementation of the project (figure 1). The reliability of the implementation of the project can provide an organizational and production model that takes into account the main parameters in the implementation of residential development. The main goal of the organizational and production model is the high economic and social efficiency of the implementation and functioning of the cluster urban residential development [13]. The consequence and logical continuation of the main goal is to achieve many private goals: economic, social, technical, technological, environmental, allowing detailed control of the parameters and promptly adjust them at all stages of the project. The ranking of goals and objectives by the degree of importance allows you to quickly make adjustments to the implementation of the project and manage risks at all stages from the concept to the commissioning of the facility (figure 2) [16]. At the same time, modeling and algorithmization of this process allow us to form a systematic approach to solving urban planning issues, taking into account optimal organizational and technological solutions that ensure the timely commissioning of safe and reliable buildings as part of the urban housing cluster. 


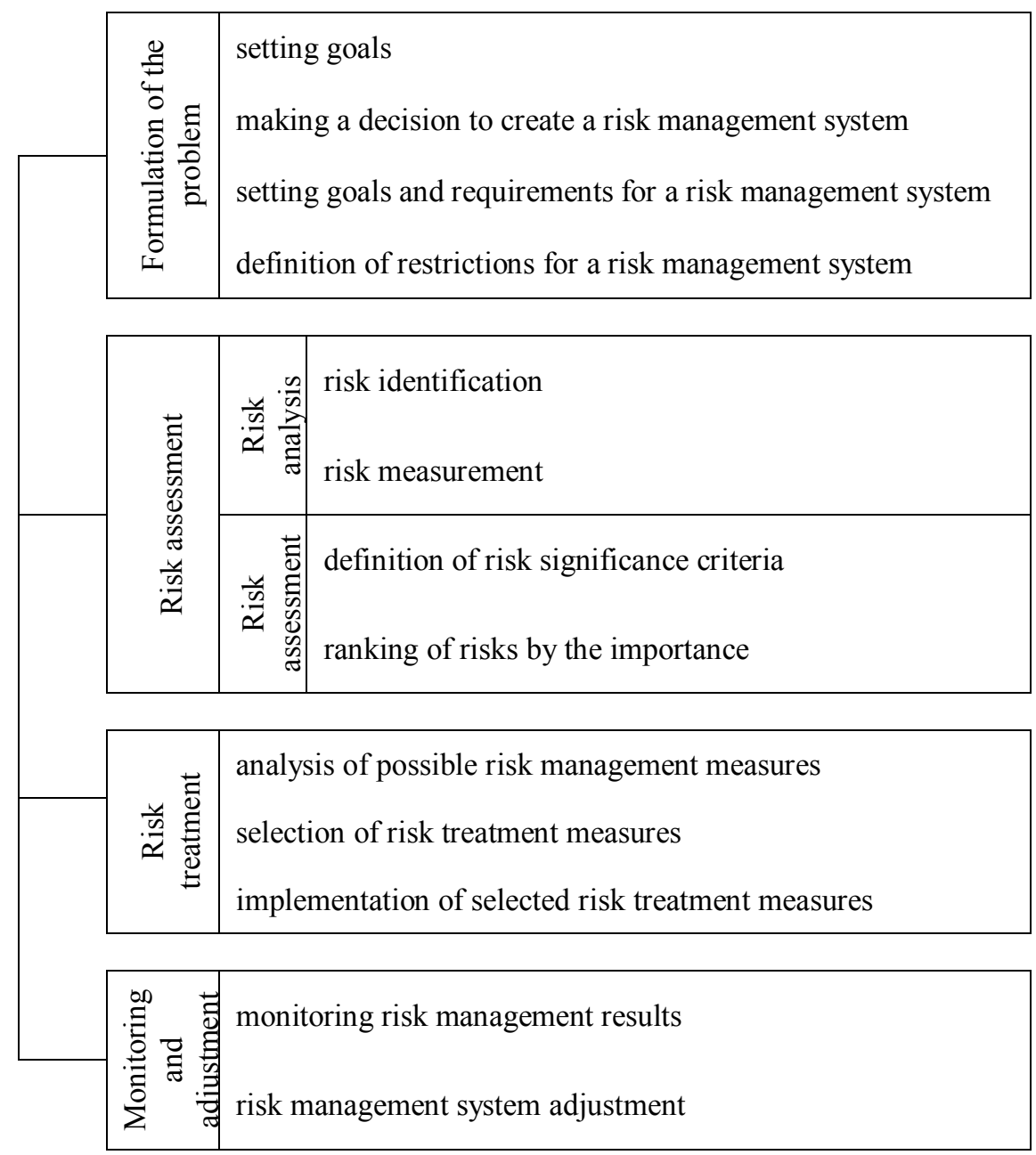

Fig. 1. General risk management scheme.

The construction industry seeks to reduce the construction cost price, risks, project implementation time and improve the work quality [17]. Systematization, automation and improvement of individual processes of technology and organization of construction in the implementation of projects occur systematically.

Automated process control systems have been developed:

ERP (Enterprise Resource Planning) is responsible for organizing the work of all departments of the organization. The main function of the system is to increase the efficiency of the use of enterprise resources due to mathematical methods of planning [2].

BI (Business intelligence) - the software which collects and comprehensive analyzes information through which business decisions are made [1]. 


\begin{tabular}{|c|c|}
\hline \multicolumn{2}{|c|}{ External unpredictable events } \\
\hline & unforeseen interference by government \\
\hline & natural disasters \\
\hline & unexpected external influences \\
\hline & uncertain circumstances and failures \\
\hline \multicolumn{2}{|r|}{ External predictable (but uncertain) events } \\
\hline & market risks due to changes \\
\hline & exploitation \\
\hline & exchange rate \\
\hline & inflation \\
\hline & tax system \\
\hline \multicolumn{2}{|c|}{ Internal non-technical events } \\
\hline & disruption of work schedules \\
\hline & interruption of financing \\
\hline & cost overruns \\
\hline \multicolumn{2}{|c|}{ Internal technical factors } \\
\hline & technology change \\
\hline & production work \\
\hline & design \\
\hline & technological risks \\
\hline \multicolumn{2}{|c|}{ Law and legal factors } \\
\hline & licenses \\
\hline & patent rights \\
\hline & contract errors \\
\hline & external claims \\
\hline & Force Majeure \\
\hline
\end{tabular}

Fig. 2. Classification of project risks.

MES (Manufacture Execution System) can manage staff, is responsible for logistics and control. It optimizes the activities of personnel, thereby reducing the cost price and improved system performance [2].

SCADA (Supervisory Control And Data Acquisition) - the software package that provides real-time operation and serves to collect, process, archive and control data [2].

WMC (Warehouse Management System) - the software, which serves to automate the operation of the warehouse and warehouse complex. This software provides centralized management of all work operations processes. [2].

PLC (Programmable logic controller) - the logic controller used to automate production operations. The controller collects, stores and converts information and provides for realtime operation [2]. 


\section{Results and discussions}

The listed systems of foreign production consider the strategic, tactical and operational levels of management, but are not specialized and narrowly specialized for the construction industry.

However, they do not allow to take into account project risks and do not propose a solution algorithm, but only systematize certain areas of kinds of activity and organize joint work of the enterprise employees.

Consider the general concept of the term "cluster":

Cluster (Eng. Cluster - congestion, brush, swarm) - the union of several homogeneous elements, representing an independent unit, which has a number of certain properties.

A cluster (urban planning) is the education of certain territory within the megapolis, which is an autonomous unit and provides the necessary set of functions, namely: residential, administrative, business, retail, recreational and recreational.

- The constituents of clusters

The concept of the advanced infrastructure residential clusters "Rodina Group" is based on the uniting of high-quality housing, educational institutions, sports and creative facilities within the boundaries of a landscaped area. The rational arrangement of all components will provide maximum comfort for living, opportunities will also be open for selfdevelopment and active pastime for all family members [12]

- The residential constituent of clusters

Civil residential buildings occupy the main area of the territory, which is created by the holding. Modern housing is building with the possibility of applying advanced innovative technologies and high-quality materials (figure 3) [12].

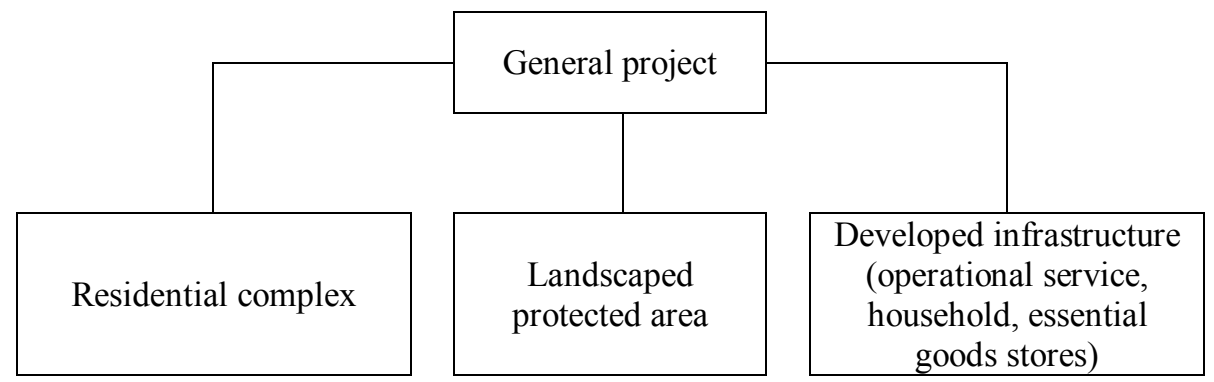

Fig. 3. General project and its constituents.

- The educational constituent

For the advanced clusters of the "Rodina Group", the educational infrastructure comprehensively approaches the solution of the tasks that consumers face (figure 4). 


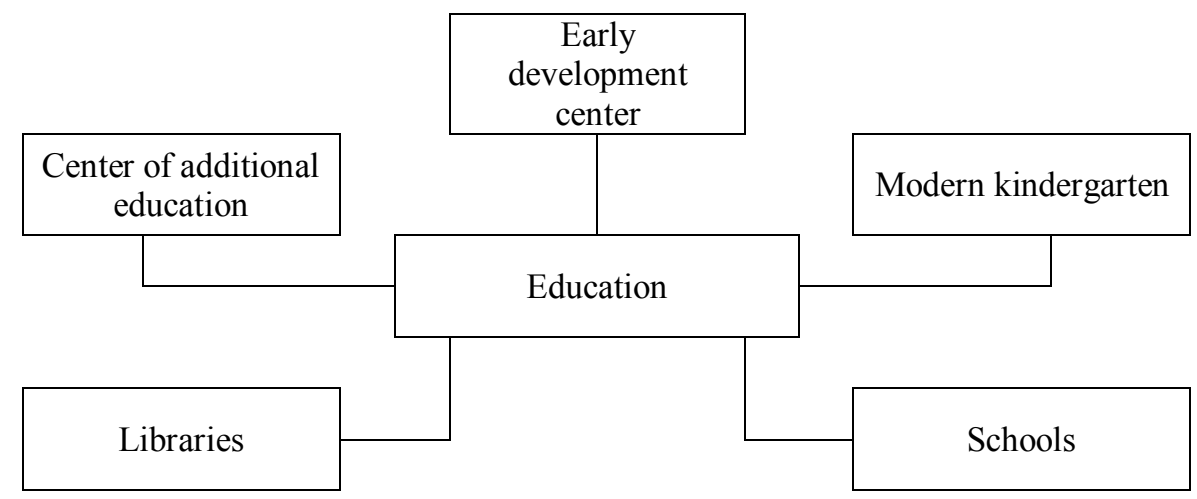

Fig. 4. The educational component of the urban cluster.

- Sports environment

In each project "Rodina Group" there are opportunities for pre-school education and high-quality general education, which go well with basic and professional sports training (figure 5).

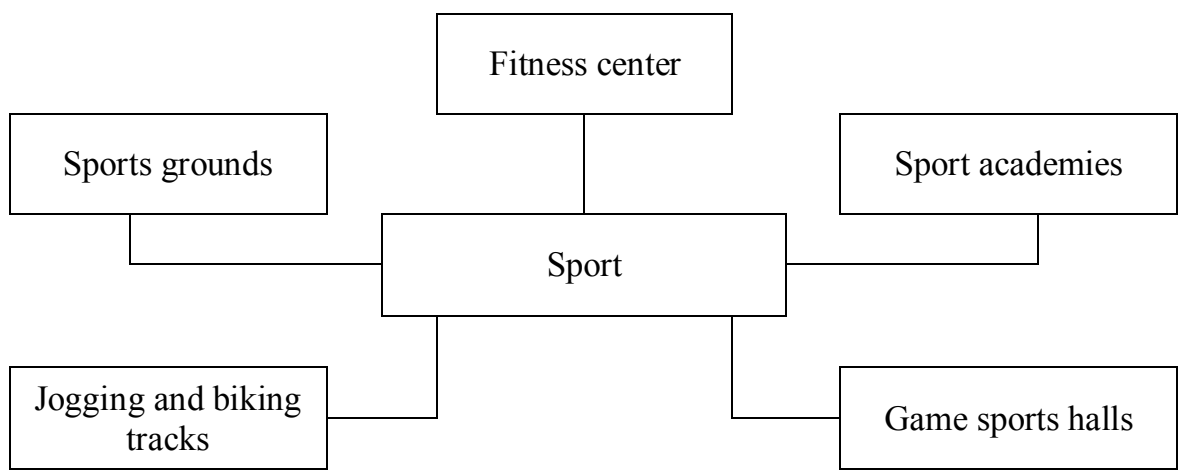

Fig. 5. The sports environment of the urban cluster.

The scientific novelty of the study lies in the formation and description of the concept of "Cluster of urban residential development", the classification and systematization of reliability indicators of the organizational and production model of cluster development, the development of a methodology for ranking the goals and tasks of the organizational and production model of cluster development, the introduction of information technologies in the planning process and organization of construction production, reducing the time for making key decisions on the project and minimization of design risks due to the analysis of risk factors at the initial stage of their occurrence. [12]

The mass introduction of specified indicators to form the optimal planning and management system at enterprises of the domestic construction industry will ensure a significant reduction in the numerical indicators of risks when introducing objects of the production program. Modelling of control systems, systems of optimal decision-making and functional systems is an urgent direction in improving construction systems engineering for the formation of a competitive production policy of an enterprise while meeting deadlines, minimizing venture decisions and the required indicators of qualimetry finished construction products.

- Organizational and technological reliability

The use of cluster technology of the organization will make it possible to provide management improvement of the social sphere of the region due to a more rational 
distribution of all types of resources, an increase in the number of organizations in the social infrastructure of the region, the rapid dissemination of innovations in their work, increasing the level of satisfaction of the population, the healthcare services quality, housing and communal services, and education, culture and leisure.

The study is based on the scientific works of scientists such as E.A. Bedrik [3], A.A. Volkov [4], A.V. Ginzburg [5], E.A. Gusakova [6, 7], A.A. Gusakov [8 -10], L.V. Kievsky [11], A.A. Lapidus [12], A.A. Morozenko [13], P.P. Oleinik [14], S.A. Sinenko [15, 16] and others.

\section{References}

1. The Gartner Glossary of Information Technology Acronyms and Terms (Gartner, 2004)

2. S. Bell, ERP, CRM, PLM working together, Lean Enterprise Systems (McGraw-Hill, 2006)

3. E.A. Bedrik, Organization of information support for micro-logistical systems of building production (2005)

4. A.A. Volkov, The methodology of designing functional control systems for buildings and structures (homeostat of construction objects) (MGSU, 2003)

5. A.V. Ginzburg, Vestnik MGSU 4-1, 251-255 (2010)

6. E.A. Gusakova, System engineering organizational and technological cycles of construction projects (MGSU, 2004)

7. E.A. Gusakova, Economics and Entrepreneurship 3-2, 869-873 (2017)

8. I. Potekhin, V. Mischenko, A. Mottaeva, A. Zheltenkov, E3S Web of Conferences, 33, 03020 (2018) doi: 10.1051/e3sconf/20183303020

9. A.A. Gusakov, System engineering construction: Encyclopedic dictionary (DIA, 2004)

10. A.A. Gusakov, Architectural and construction designing. Methodology and Automation (Stroyizdat, 1986)

11. L.V. Kievsky, F.F. Dzhalilov, Industrial and Civil Engineering 4, 24 (1995)

12. A.A. Lapidus, A.O. Feldman, Vestnik MGSU 11, 193-201 (2015)

13. A.A. Morozenko, Industrial and Civil Engineering 7, 49-51 (2015)

14. S.A. Sinenko, System Engineering and Computer Science 72 (1992)

15. S.A. Sinenko, V.M. Ginzburg, V.N. Sapozhnikov, P.B. Kagan, A.V. Ginzburg, Automation of organizational and technological design in construction (Publishing house ASV, 2002)

16. D.V. Topchy, Technology and organization of construction production 4-1, 34-41 (2015)

17. D.V. Topchy, Technology and organization of construction production 3, 40-42 (2014)

18. D.V. Topchy, Science of Science 6 (2017) 